\title{
ATUAÇÃO DO PODER LEGISLATIVO ESTADUAL: ANÁLISE DOS INCENTIVOS DOS DEPUTADOS ESTADUAIS NA ATIVIDADE LEGISLATIVA
}

\author{
DÉBORA COSTA FERREIRA ${ }^{1}$ \\ FERNANDO BOARATO MENEGUIN ${ }^{2}$ \\ MAURÍCIO SOARES BUGARIN ${ }^{3}$
}

RESUMO: Estudos empíricos explicitam a ineficiência das assembleias legislativas na produção de leis que impactem positivamente a sociedade. Nesse contexto, o presente estudo analisa a estrutura de incentivos que incide sobre os deputados estaduais e distritais no momento de propor projetos de lei, por meio da construção de modelagem econômica, a qual leva à conclusão de que o atual desenho institucional dos estados tem gerado incentivos para que esses deputados produzam leis particularistas, irrelevantes e/ou inconstitucionais. A partir da análise, conclui-se que de nada adianta expandir as atribuições constitucionais dos deputados estaduais se esses não possuírem competência técnica para elaborar leis e políticas públicas que melhorem o bem-estar da sociedade como um todo ou para realizar atividades fiscalizatórias e se o controle de constitucionalidade de leis estaduais não for efetivo.

Palavras-Chave: Análise Econômica do Direito; Federalismo; Autonomia federativa; Incentivos no Legislativo estadual.

\footnotetext{
${ }^{1}$ Mestre em Direito Constitucional no Instituto Brasiliense de Direito Público - IDP. Email: debora.costaferreira91@gmail.com

2 Doutor em Economia pela Universidade de Brasília. Pós-Doutor em Análise Econômica do Direito pela Universidade da California/Berkeley. Professor titular do IDP. E-mail: fbmeneguin@hotmail.com

${ }^{3}$ MSc e PhD em Economia pela University of Illinois. Professor titular do Departamento de Economia da Universidade de Brasília. E-mail: bugarin.mauricio@gmail.com
} 


\title{
STATE LEGISLATIVE CHAMBERS PERFORMANCE: ANALYSIS OF INCENTIVES OF THE STATE REPRESENTATIVES IN THE LEGISLATIVE ACTIVITY
}

\begin{abstract}
Empirical studies show legislative assemblies to be inefficient in producing laws that carry positive impact to society. In this context, we analyze the incentives' structure that influences the state or district representatives at the moment of proposing bills, by means of an economic model, which leads to the conclusion that the current institutional design of states' institutions has generated incentives for these agents to produce particularistic, irrelevant and/or unconstitutional laws. From the analysis, it is concluded that there is no effectiveness in expanding the constitutional attributions of state deputies if they do not have the technical competence in the elaboration of laws and public policies that improve the welfare of society as a whole or to carry out inspection activities and if constitutional review of state laws is not effective.
\end{abstract}

KEYWORDS: Economic Analysis of Law; Federalism; Federative autonomy; Incentives of State Legislative Branch. 


\section{REVISTA ESTUDOS INSTITUCIONAIS}

\section{INTRODUÇÃO}

Há crescente tendência jurisprudencial no Supremo Tribunal Federal no sentido da adoção dos pressupostos das teorias federalistas norteamericanas para ampliar as atribuições dos entes subnacionais ao interpretar normas de repartição de competências. Propaga-se como benefícios a expansão da base empírica de experiências constitucionais para a tomada de decisões legislativas mais seguras e a ampliação da liberdade individual dos cidadãos na escolha entre os estados que lhes provejam o melhor conjunto de bens e serviços públicos.

De todo modo, a estrutura de incentivos moldada a nível subnacional pode prejudicar a verificação de uma direta relação de causa e efeito entre a abertura do federalismo e os benefícios acima mencionados (HOSLI, 1995 , p. 162). Isso porque, se os atores políticos e institucionais subnacionais não receberem corretos incentivos, provavelmente não se empenharão na produção de legislação relevante, inovadora e que busque o aprimoramento da realização do interesse público e da efetivação de direitos fundamentais dos jurisdicionados, ainda que seja expandido seu rol de competências. Nessa situação, não haverá significativos benefícios na ampliação da autonomia dos entes, visto que não será, de fato, expandida a base empírica de experiências institucionais que conduza à efetiva possibilidade de escolha entre boas alternativas, bem como à aprendizagem dos entes federativos. Pode ocorrer, inclusive, retrocesso institucional, em decorrência da passagem de importantes competências constitucionais a entes menos eficientes e menos equipados para a sua realização.

Atualmente, conforme será ilustrado na seção 2, análises empíricas acerca da atuação das assembleias legislativas brasileiras demonstram alto grau de ineficiência da sua produção legislativa, com relação aos recursos investidos para essa atividade, assim como a baixa substancialidade no conteúdo dessas leis, em termos de impacto para o bem-estar social, sendo que representativa parcela delas é posteriormente julgada inconstitucional.

Assim, parece que a modelagem institucional vigente leva os membros do poder legislativo estadual a produzir leis irrelevantes, particularistas ou até inconstitucionais. Mas será que a mera ampliação das competências constitucionais é capaz de conduzir a uma situação de bom funcionamento das assembleias legislativas, nos moldes das previsões teóricas? Ou existem outros fatores em jogo que moldam os incentivos dos deputados estaduais? Eis o que o presente estudo visa a investigar. 
Nesse contexto, questiona-se: quais os fatores que geram incentivo aos parlamentares para a produção de leis particularistas, irrelevantes e inconstitucionais no âmbito estadual? Quais fatores conduzem ao desincentivo da criatividade legislativa, do alinhamento ao interesse público e do aproveitamento de experiências bem-sucedidas de outros estados pelos membros das assembleias legislativas, seja pela atividade legiferante, seja pela função fiscalizatória? E quais alternativas de desenho de incentivos podem ser propostas de modo a possibilitar o efetivo controle de desvios na atividade parlamentar estadual e a realização prática das projeções teóricas traçadas para a descentralização do modelo federativo?

Para conduzir essa investigação, lança-se mão da teoria econômica da decisão para reproduzir a escolha do deputado estadual no momento de decidir como despenderá esforços na atividade parlamentar, com vistas a maximizar o número de votos na próxima eleição. $\mathrm{O}$ modelo resgata outra função normalmente esquecida pelos poderes legislativos nacionais, mas que é objeto de ampla utilização nos legislativos de estáveis Estados democráticos ao redor do mundo - a função fiscalizatória, que ganha destaque nos países vinculados à OCDE, por meio da promoção de avaliações ex-ante e ex-post das proposições legislativas e das políticas públicas vigentes ${ }^{4}$.

A partir do resultado do modelo, conclui-se que de nada adianta expandir as atribuições constitucionais dos deputados estaduais - seja pela interpretação extensiva das regras de repartição de competências pelo STF, seja pela possibilidade de proposição de projetos de leis conjuntos entre deputados estaduais e governadores - , (i) se esses não possuírem competência técnica para elaborar políticas públicas que melhorem o bem-estar da sociedade como um todo, bem como para realizar atividades fiscalizatórias e (ii) se o controle de constitucionalidade de leis estaduais não for efetivo. Nesses casos, assim como no cenário atual, os deputados terão incentivos para propor leis inconstitucionais, particularistas e irrelevantes. Outro insight que deriva da modelagem econômica é a de que, enquanto não expandidos suficientemente esse rol de competências constitucionais dos deputados, a função fiscalizatória é a alternativa que maximiza o bem-estar social, na situação em que o sistema de controle de constitucionalidade de leis estaduais é efetivo e o parlamentar é competente em termos técnicos para essa atividade.

\footnotetext{
4 Ver The role of parliaments in promoting better regulation. Disponível em: $<$ https://www.oecd.org/regreform/regulatory-policy/conference-on-role-ofparliaments.htm>. Acesso em: 29 nov. 2018.
} 


\section{REVISTA ESTUDOS INSTITUCIONAIS}

A seguir, o estudo desenvolve sua análise a partir da seguinte organização: apresentam-se diagnósticos empíricos acerca da atuação das assembleias legislativas e, em seguida, apresentam-se os aspectos principais que influenciam na decisão dos deputados estaduais, para então propor modelagem econômica. Enfim, tecem-se as conclusões.

\section{Diagnóstico Da ATIVIDADE PARLAMENTAR ESTADUAL}

Estudos acerca da atuação das assembleias legislativas têm diagnosticado padrão de produção de grande quantidade de leis "de cunho 'clientelista', de 'baixa qualidade' e 'não relevantes'" (FIGUEIREDO, 2012, p. 10), sendo que parte representativa delas é declarada inconstitucional posteriormente, seja pelo Supremo Tribunal Federal, seja pelo Tribunal de Justiça estadual (VIANNA; BURGOS; SALLES, 2007, p. 39-85).

Ao comparar a produção legislativa em 2016 de vinte e sete assembleias legislativas do Brasil - incluindo a Câmara Legislativa do Distrito Federal - sob o ângulo quantitativo e qualitativo, Leonardo Sales (2017) constatou (i) a baixa eficiência da maior parte delas, se comparado com o alto custo que representam para o orçamento estadual, e (ii) a baixa relevância das leis produzidas, considerando que ao menos $65 \%$ das leis veiculam conteúdos sem importância efetiva para os cidadãos, como as que criam datas comemorativas, que estabelecem denominação de ruas, praças, unidades administrativas, etc; ou as que concedem título de cidadão honorário ou moções.

No estudo, apresenta-se tabela que define os temas mais frequentes encontrados nas leis analisadas: 
Tabela 1 - classificação das leis estaduais de 2016

Tópico

Declarações de utilidade pública

Regulação de programa ou serviço público

Criação de datas comemorativas

Alterações no orçamento do estado

Regulação de atividade comercial

Criação de normas referentes aos servidores estaduais

Regulação da estrutura administrativa estatal

Denominações de ruas, praças, unidades administrativas etc.

Autorizações para compra, cessão ou alienação de imóveis públicos

Legislação tributária do estado

Concessão de Título de cidadão
Percentual de Leis

$26,80 \%$

$14,90 \%$

$12,70 \%$

$8,40 \%$

$7,50 \%$

$7,40 \%$

$7 \%$

$5 \%$

$3,90 \%$

$3,80 \%$

$2,60 \%$

Da tabela também se observam leis que tendem a veicular interesses particularistas, tal como as declarações de utilidade pública (as quais facilitam que as entidades assim definidas recebam recursos públicos do estado sem licitação, conforme conclusão do próprio autor), ou ainda as criações de normas referentes aos servidores estaduais e regulação da atividade comercial. Com efeito, outra percepção que se extrai é a de que, tanto grupos de interesse do funcionalismo público, quanto aqueles de natureza privada podem estar tendo espaço eficaz para veiculação de suas demandas.

Além disso, dados do Anuário da Justiça Brasil 2018 (CONSULTOR JURÍDICO, 2018) revelaram que $78 \%$ das ações diretas de inconstitucionalidade ajuizadas no STF contra leis de autoria de assembleias legislativas são julgadas inconstitucionais. 


\section{REVISTA ESTUDOS INSTITUCIONAIS}

Essa alta taxa de invalidação também se verifica nas Justiças Estaduais ${ }^{5}$. Nos últimos sete anos, por exemplo, o Tribunal de Justiça do Distrito Federal e Territórios e o Supremo Tribunal Federal confirmaram a inconstitucionalidade de $77 \%$ das leis aprovadas pela Câmara Legislativa questionadas pelo Ministério Público do Distrito Federal e Territórios (ALMEIDA; RODRIGUES, 2017).

Mas o que tem incentivado os deputados a produzirem leis particularistas, irrelevantes e inconstitucionais? Para responder essa pergunta, a seção seguinte debruça-se sobre a análise estratégica do comportamento dos membros das assembleias legislativas, permeando peculiaridades institucionais dos estados que influenciam a decisão desses agentes acerca de sua atuação legislativa. A hipótese adotada pelo presente estudo é a de que, como será exposto a seguir, existem outros fatores em jogo que moldam os incentivos dos deputados estaduais, para além do tamanho do rol de competências constitucionais.

\section{QUAIS SÃO OS INCENTIVOS DOS DEPUTADOS ESTADUAIS?}

De fato, é praticamente unânime entre os doutrinadores a posição de que o modelo federativo brasileiro reserva pouco poder de atuação aos estados-membros (ALMEIDA, 2000), seja porque aos Municípios e à União foi estabelecido amplo rol de competências, seja pelo exíguo espaço deixado aos entes estaduais quando da sobreposição de competências concorrentes (ABRUCIO, 2005, p. 49; TAVARES, 2008).

Soma-se a isso a concentração de competências importantes para o governador, em razão do princípio da simetria (LEONCY, 2011), diminuindo mais ainda a margem de atuação do deputado estadual para que sua produção legislativa impacte positivamente a população como um todo. Em razão disso, em todas as constituições estaduais, o governador possui competência privativa para iniciar projetos de lei que impliquem aumentos de despesas para a Administração Pública; criação, estruturação, e atribuições de órgãos ou entidades públicas estaduais e ordenação territorial. Essas e outras competências relacionam-se intimamente às prerrogativas para elaboração de políticas públicas que atinjam amplo espectro da sociedade. Por isso, ampliar simplesmente as competências estaduais não expandiria, por si só, a capacidade dos membros do Poder Legislativo de proporem leis relevantes para a sociedade.

\footnotetext{
${ }^{5}$ Esclarece-se que o controle de constitucionalidade de leis estaduais pode ser realizado tanto pelo Supremo Tribunal Federal quanto pelos Tribunais de Justiça Estaduais, o que será melhor explicado mais à frente.
} 
Destarte, em conjunto com a descentralização do modelo federativo e a maior parcimônia no uso do princípio da simetria pelo STF ou pelo Tribunal de Justiça estadual, uma solução possível seria a previsão da possibilidade de proposição conjunta de projetos de lei entre Poder Legislativo e Executivo estaduais, para que os deputados possam se beneficiar da publicidade eleitoral decorrente de proposições legislativas que envolvam matéria de competência privativa do governador para iniciar projetos de lei e de emenda à Constituição Estadual.

Com efeito, extrai-se que os membros do Poder Legislativo estadual, no atual modelo legislativo, possuem baixa competência constitucional de desenvolver políticas públicas consistentes, que melhorem o bemestar social dos jurisdicionados como um todo. Diante desse quadro, resta para eles maximizar o número de votos nas próximas eleições por meio de outras estratégias que trazem menores retornos eleitorais e/ou sociais.

Uma primeira alternativa seria a obtenção de apoio de grupos de interesse com suficiente representatividade eleitoral, apresentando projetos de lei que veiculam interesses particularistas. Segundo cientistas políticos ${ }^{6}$, a aprovação de projetos de lei particularistas é facilitada pelo mecanismo de coordenação para aprovações recíprocas de projetos de interesses particularistas, comumente instituído nas assembleias legislativas dos estados e denominado de sistema log-rolling, o qual é alimentado e fortalecido pela eficaz atuação de grupos de interesse na cooptação de instâncias políticas ${ }^{7}$.

A segunda alternativa para maximizar as chances de reeleição é a produção legislativa irrelevante ${ }^{8}$, incrementalista ou repetitiva, no âmbito da competência que ainda lhes resta, encontrando meios para manterem e obterem maior apoio político a partir da publicidade dessas medidas em termos legislativos. O sucesso dessa estratégia irá depender do grau de esclarecimento da população quanto à qualidade dessa produção legislativa. Quanto maior a ignorância da sociedade quanto a esse aspecto, maiores serão as perdas sociais, diante da mobilização da máquina estatal para algo que não traz retornos sociais.

Uma outra estratégia usada como medida eleitoreira é apresentação de leis sabidamente inconstitucionais e populistas, com extrapolação de competências constitucionais que, de fato, prejudicam o funcionamento governamental por se sobreporem a competências inequívocas de outros entes e Poderes e desregularem as regras das políticas públicas vigentes.

\footnotetext{
${ }^{6}$ Gabriel Bellon (2016, p. 153) apontou evidências do funcionamento do sistema de logrolling entre os diferentes grupos político-partidários.

${ }^{7}$ Esse fenômeno social ocorre, sobretudo, em menores níveis de governo (HOSLI, 1995).

${ }^{8}$ Aí se incluem as moções, concessões de títulos de cidadãos honorários e homenagens.
} 


\section{REVISTA ESTUDOS INSTITUCIONAIS}

A lógica por trás dessa estratégia é enganar os eleitores, oferecendolhes soluções sociais aparentemente simples e satisfatórias, mas que omitem a incompetência do deputado para tomar aquela medida, apostando que a lei não será invalidada pelo Poder Judiciário antes da próxima eleição 9 . Apesar de a atuação do deputado parecer boa para todos em um primeiro momento, ela gera mais prejuízos do que benefícios, por sobrepor atribuições. Por exemplo: propor a gratuidade de serviços públicos parece beneficiar amplo espectro do eleitorado, mas, se levada a cabo, a medida irá gerar grande prejuízo social ao onerar o Estado sem o devido planejamento financeiro, o que poderia resultar em aumento de tributos no futuro.

Esse tipo de proposição não envolve custos consideráveis para os deputados, uma vez que não se dão ao trabalho de saber até onde podem ir e onde já existe atuação, para evitar sobreposição de competências federativas. Assim, o desincentivo dessa estratégia depende tanto de um controle de constitucionalidade efetivo, capaz de invalidar as leis inconstitucionais antes da obtenção do retorno eleitoral, quanto do esclarecimento da população acerca do que o deputado efetivamente pode fazer.

Como alternativa a essas limitações constitucionais e a essas atividades legislativas insatisfatórias sob o ponto de vista público, existe função normalmente esquecida pelos poderes legislativos nacionais, mas que é objeto de amplo entusiasmo e investimento nos legislativos internacionais: a função fiscalizatória. Além de propiciar maior correção na execução de políticas públicas vigentes, surgem, no decorrer do processo de avaliação de resultados, insights e soluções legislativas criativas para proposição de políticas públicas futuras, efetivamente inspiradas nas experiências dos entes subnacionais, tanto as bemsucedidas quanto as malsucedidas.

Mais ainda, essa atividade fiscalizatória ativa melhora a situação dos jurisdicionados e, portanto, tem condições efetivas de se reverter em votos na próxima eleição. Assim, uma maneira de escapar dessas limitações legislativas e criar espaço para o Legislativo estadual trabalhar no sentido de melhorar o bem-estar social é não estar tão focado na função legiferante e investir na função fiscalizatória. Isso já vem acontecendo em algumas Assembleias Legislativas. $\mathrm{O}$ caso mais paradigmático é o da Assembleia de Minas Gerais - ALMG, que criou uma plataforma de

\footnotetext{
9 Desconsidera-se, a título de simplificação da análise, o poder de veto dos demais membros da assembleia legislativa e do governador, supondo-se a situação em que esses controles não têm sua eficácia garantida por razões político-partidárias.
} 
avaliação de políticas públicas - "Políticas Públicas ao seu Alcance" (MINAS GERAIS, 2018).

A iniciativa possibilita tanto a sociedade acompanhar o trabalho do Poder Executivo quanto facilita a atuação dos deputados estaduais no sentido de contribuírem e aperfeiçoarem as políticas públicas vigentes, bem como as propostas de novas políticas públicas que, por precisarem de aprovação do Poder Legislativo, tramitarão na forma de proposição e serão debatidas no decorrer do processo legislativo.

Destarte, com essa nova alternativa, o deputado estadual pode, para maximizar o número de votos na próxima eleição: (a) propor projeto de lei que estabeleça política pública capaz de aumentar o bem-estar da sociedade em geral, para obter apoio da população como um todo até que a lei seja declarada inconstitucional por vício de competência; (b) propor projetos de lei que veiculem interesses particularistas, para conseguir votos dos integrantes dos grupos beneficiados; (c) propor projeto de lei irrelevante, para angariar votos a partir da publicidade de sua produtividade legislativa, em termos quantitativos; (d) propor projeto de lei inconstitucional e populista, de modo a obter votos dos eleitores, omitindo-se o fato de não ter competência para tanto; ou (e) realizar atividade de fiscalização, a qual beneficia toda sociedade diante da melhor qualidade das prestações e gastos públicos.

Sob essa escolha incidem dois fatores essenciais: (i) a competência individual ou institucional, sob o ponto de vista técnico e da experiência na produção de políticas públicas e na fiscalização do governo; e (ii) a efetividade do sistema de controle de constitucionalidade para invalidar leis inconstitucionais.

Em relação ao primeiro fator: a competência a que se refere esse ponto não diz respeito à repartição de atribuições constitucionais para a atividade legislativa, mas sim à capacidade individual ou institucional para realizar essas atividades e a função fiscalizatória.

O deputado que melhor compreende o funcionamento da Administração Pública, os gargalos das políticas públicas vigentes e os efetivos meios para aprimorá-las, terá maior capacidade para propor projetos de leis que melhorem a vida da sociedade e para fiscalizar as políticas vigentes. Se isso não é de conhecimento e domínio do deputado, a obtenção dessas informações e diagnósticos será mais custosa para produzir proposições legislativas e propostas de políticas públicas complexas o bastante para oferecer soluções a problemas sociais, incluindo-se aí os elevados custos de experimentar e de pesquisar experiências bem-sucedidas, essenciais às teorias dos laboratórios legislativos. Isso dependerá tanto do preparo técnico do próprio parlamentar quanto da sua habilidade de formar equipe que possua as 


\section{REVISTA ESTUDOS INSTITUCIONAIS}

competências técnicas necessárias, seja com servidores concursados, seja com assessores que ocupem cargos comissionados.

Assim, essa competência também é afetada por fatores institucionais. Se a Assembleia Legislativa for composta por profissionais qualificados em processo legislativo e em avaliação de políticas públicas e de dados a ela relacionados, estabelecendo-se centro de competência para desempenho dessas atividades, o custo dos deputados estaduais será muito menor para desempenhar suas funções, porque poderão dispor de toda infraestrutura já instalada para tanto. Por exemplo, um membro da Assembleia Legislativa de Minas Gerais terá menores custos de fiscalizar políticas do governo estadual do que o de outro estado cujo Poder Legislativo não desempenhe usual e efetivamente esse papel.

Incide, no ponto, o efeito da sinalização. Se o deputado for competente, em termos de competência técnica individual, ele poderá sinalizar melhor sua competência para os eleitores por meio do desempenho da atividade fiscalizatória ou na proposição de boas políticas públicas, diminuindo a assimetria de informação dos eleitores. Desse modo, o retorno eleitoral com a fiscalização mais do que compensará o custo adicional incorrido ao escolher uma dessas estratégias, com relação à proposição de política particularista ou a irrelevante - opções que os igualam aos incompetentes.

Sobre o segundo fator, a efetividade do controle de constitucionalidade realizado pelo Poder Judiciário também é essencial para determinar os incentivos dos deputados estaduais. Tal efetividade envolve tanto a propensão dos agentes legitimados ${ }^{10}$ para propor as ações de controle de constitucionalidade quanto a eficiência e eficácia do sistema de controle de constitucionalidade de leis, seja pelo STF, seja pelo Tribunal de Justiça do respectivo estado ${ }^{11}$.

$\mathrm{Na}$ situação atual, em que há expressivas limitações quanto às atribuições constitucionais ao Poder Legislativo estadual, se o parlamentar previr que os mecanismos de controle de constitucionalidade não estão funcionando de forma efetiva a ponto de garantir a invalidação de lei inconstitucional por vício de iniciativa antes das próximas eleições, ele terá incentivos para propor a medida legislativa que tenha maior alcance social apesar de não ter competência

\footnotetext{
${ }^{10}$ Os legitimados para interporem ações de controle concentrado de constitucionalidade encontram-se relacionados no artigo 103 da Constituição Federal.

${ }^{11} \mathrm{O}$ controle de constitucionalidade de leis estaduais pode ser feito tanto pelo STF, com base na Constituição Federal, quanto pelo Tribunal de Justiça Estadual, tendo como parâmetro a Constituição do respectivo Estado e, no caso de controle difuso, o parâmetro é a própria Constituição Federal.
} 
para tanto, aproveitando-se (i) da publicidade da mera apresentação da proposta e (ii) do aumento de apoio político decorrente dos efeitos que tais leis produzam no período de tempo entre sua aprovação e declaração de inconstitucionalidade, sobretudo quando essa é proferida com efeitos ex nunc. Nesse caso, contudo, os benefícios da proposição só se perpetuarão para o parlamentar que auferir ganhos eleitorais, visto que a lei será declarada inconstitucional em momento futuro, cessando os benefícios sociais dela decorrentes.

Caso contrário, se o sistema judicial for efetivo - aqui considerado aquele que invalida a lei inconstitucional somente antes das próximas eleições -, o deputado estadual não terá benefícios eleitorais ao propor tal lei. Ainda nesse caso, a sociedade em nada se beneficia com essa medida.

A partir da apresentação de todos esses aspectos que influenciam os incentivos dos deputados estaduais, constrói-se modelagem econômica que visa a representar o ambiente de escolha racional desses deputados no contexto atual e na hipótese da expansão das suas competências constitucionais.

\section{Modelagem eCONÔMICA}

\section{Elementos do Modelo}

\subsection{Estratégias}

No modelo proposto, assume-se que o deputado estadual atua com vistas a maximizar o número de votos na próxima eleição. A partir desse objetivo, ele decide acerca de como desempenhará sua função legislativa, observando o benefício líquido que irá obter com as seguintes estratégias possíveis:

a. Estratégia a: propor projetos de lei que estabeleçam boas políticas públicas ou melhore as já vigentes, de modo a aumentar o bem-estar da sociedade em geral, com vistas a obter apoio da população como um todo na próxima eleição;

b. Estratégia b: propor projetos de leis que veiculem interesses particularistas, para conseguir votos dos integrantes dos grupos beneficiados;

c. Estratégia c: propor projetos de leis irrelevantes, para angariar votos a partir da publicidade de sua produtividade legislativa, em termos quantitativos;

d. Estratégia d: propor projetos de lei inconstitucionais e populistas, que veiculam soluções simplistas e, aparentemente, benéficas para a sociedade como um todo, para obter amplo 


\section{REVISTA ESTUDOS INSTITUCIONAIS}

retorno eleitoral, omitindo-se $\mathrm{o}$ fato de invadirem perniciosamente a competência de outros entes ou de outros Poderes; e

e. Estratégia e: realizar atividades de fiscalização, as quais trazem alto retorno eleitoral ao beneficiar ampla parcela da sociedade a partir da maior eficiência do gasto público e da diminuição do problema agente-principal.

\subsection{Utilidade}

Para levar adiante a estratégia $p \in\{a, b, c, d, e\}$, o deputado incorre um custo pessoal $c_{p}$. Por outro lado, também recebe um benefício eleitoral. Seja $\sigma(E)$ um parâmetro que mede o retorno eleitoral do projeto para o deputado, visto como um percentual da população relevante, $b$, que vota nesse político em função do projeto correspondente. Assim, se o deputado aprovar o projeto $p \in\{a, b, c, d, e\}$, seu retorno eleitoral será $\sigma_{p}(E) b$. Destarte, considerando o benefício e o custo do projeto para o deputado em adotar o projeto, sua utilidade será:

$$
U(p)=\sigma_{p}(E) b-c_{p}
$$

A variável $E$ reflete a qualidade institucional do Estado, que pode ser de dois tipos, conforme descrito abaixo.

\subsection{Tipos de Estados}

i. Com sistema de controle de constitucionalidade efetivo: há rápida impugnação de políticas inconstitucionais, capaz de invalidar uma lei inconstitucional em tempo hábil para que a proposição dessa lei não traga retornos eleitorais para o seu proponente; trata-se do Estado do tipo $E=C E$.

ii. Com sistema de controle de constitucionalidade inefetivo: em que não se invalida leis inconstitucionais antes da eleição, permitindo que o deputado estadual autor da proposição se beneficie dessa estratégia em termos eleitorais; trata-se do Estado do tipo $E=C I$.

Portanto, o tipo do Estado afetará o potencial de retorno eleitoral das políticas inconstitucionais, $p=d$, de forma que $\sigma_{d}(C E)=0$ enquanto $\sigma_{d}(C I)=1$.

\subsection{Custos}


Quanto à relação entre os diferentes custos, formulam-se as seguintes hipóteses:

a. Estratégia a: Há significativos custos para o deputado estadual produzir projetos de lei e políticas públicas efetivamente capazes de melhorar a condição de vida dos habitantes em geral, $c_{a}$, porquanto exige-se alto nível de esforço para a obtenção do conhecimento técnico e experiência necessários para se propor boas soluções sociais - ou, nos termos da teoria dos laboratórios legislativos, para pesquisar boas experiências observadas em outros estados;

b. Estratégia b: Há baixo custo de se propor projetos de leis particularistas, relacionados à obtenção de apoio dos demais parlamentares para aprovação do seu projeto, $c_{b}$, o que é facilitado pelo sistema de log-rolling;

c. Estratégia c: Inexiste custo em se propor projetos de lei irrelevantes, $c_{c}=0$, visto que não demanda significativo esforço intelectual, como para a criação de dia em calendário oficial ou a denominação de ruas;

d. Estratégia d: Tampouco há custos em se aprovar leis inconstitucionais e populistas, $c_{d}=0$, porquanto constituem soluções simples para os problemas dos cidadãos, mas que só dariam certo no caso de o deputado não ter qualquer limite institucional, com relação a outras esferas federativas ou aos demais Poderes - o deputado não incorre em qualquer custo em verificar possíveis sobreposições de competências e possíveis distorções geradas pela medida; e

e. Estratégia e: As atividades fiscalizatórias também envolvem custos relativamente altos, $c_{e}$, referentes ao esforço de auditar e acompanhar as contas de governo e a execução das ações governamentais. Estima-se que esses custos sejam bem próximos aos da estratégia " $a$ ", ainda que menores.

Assim, tem-se que:

$$
c_{a}>c_{e} \gg c_{b}>c_{c}=c_{d}=0
$$

$\operatorname{com} c_{a}$ relativamente próximo de $c_{e}$.

\subsection{Tipos de políticos}




\section{REVISTA ESTUDOS INSTITUCIONAIS}

O modelo, com base nos fundamentos acima descritos, também leva em conta dois tipos de políticos e dois tipos de estado.

i. Competente: possui menor custo para propor projetos de lei $\left(c_{a}\right.$ e $\left.c_{b}\right)$ e desempenhar a atividade legislativa $\left(c_{e}\right)$;

ii. Incompetente: incorre em maiores custos para propor projetos de lei $\left(\overline{c_{a}}\right.$ e $\left.\overline{c_{b}}\right)$ e seu custo para desenvolver a atividade fiscalizatória é muito mais elevado do que o do político competente, consoante explicitado na seção que tratou dos elementos

$$
\left(\overline{c_{e}}\right): \overline{c_{p}}>\underline{c_{p}}, p=a, b, e, \overline{c_{e}} \gg \underline{c_{e}}
$$

Portanto, as utilidades acima dependem do tipo do político, de forma que, para o político competente tem-se: $\underline{U}(p ; E)=\sigma_{p}(E) b-c_{p}$ e para o político incompetente tem-se: $\bar{U}(p)=\bar{\sigma}_{p}(E) b-\overline{c_{p}}$. Nota-se que o benefício eleitoral não depende do tipo de político, uma vez que os eleitores não observam a competência do deputado, mas depende do ambiente institucional em que se encontra o Estado correspondente $(E)$.

\subsection{Retornos eleitorais}

Acerca dos retornos eleitorais $\sigma_{p}(E)$, tem-se que:

a. Estratégia a: propondo leis e políticas públicas que beneficiam a sociedade como um todo, o deputado estadual terá amplo retorno eleitoral $(b)$, exceto se as Assembleias legislativas estaduais não possuírem autonomia institucional para produzir tais leis (0). Temos, portanto, duas situações possíveis. Na situação atual, em que as assembleias estaduais não têm competência para produzir a maioria das leis de espectro geral que beneficiam toda a sociedade, temos $\sigma_{a}(E)=$ 0 . Já no sistema discutido em que é dada maior autonomia às Assembleias estaduais, tais leis se tornam acessíveis aos deputados, de forma que $\sigma_{a}(E)=1$. Analisar-se-á inicialmente a situação atual para, posteriormente, se analisar a situação de descentralização de autoridade legislativa.

b. Estratégia b: apresentar projetos particularistas permite que o deputado angarie votos da parcela da sociedade beneficiada $\sigma_{b}(E)=\alpha, 0<\alpha<1$, independentemente do ambiente institucional $E$.

c. Estratégia c: ao propor projetos de lei irrelevantes, obtém-se algum retorno decorrente da publicidade com a produtividade legislativa, $\sigma_{c}(E)=\beta, 0<\beta<1$, que dependerá do nível de 
esclarecimento da população acerca da qualidade da produção legislativa. No entanto, esse benefício eleitoral será mais diluído, de forma que $\beta<\alpha$.

d. Estratégia d: projetos de lei inconstitucionais, trarão retornos eleitorais por seu conteúdo populista $(b)$, exceto se o sistema de controle de constitucionalidade for efetivo (0). Portanto, $\sigma_{b}(C E)=0$ e $\sigma_{b}(C I)=1$.

e. Estratégia e: a sociedade percebe em algum nível a atividade fiscalizatória e confere apoio eleitoral ao deputado que a realizou nas urnas, $\sigma_{c}(E)=\gamma$. Esse reconhecimento é maior que aquele obtido por meio de projetos particularistas ou de leis irrelevantes, i.e. $\gamma>\alpha>\beta$.

\subsection{Hipóteses sobre relações entre custos e benefícios}

i. Quanto ao parlamentar competente, assume-se que o maior retorno eleitoral com a fiscalização (estratégia " $e$ ") mais do que compensa o custo adicional que o parlamentar competente terá ao escolher essa estratégia, com relação à proposição de política particularista (estratégia “ $b$ ”) ou a irrelevante (estratégia " $c$ "), visto que poderá sinalizar melhor sua competência para os eleitores, diminuindo a assimetria de informação dos eleitores. Matematicamente, essa hipótese pode ser expressa por duas expressões:

$$
\begin{gathered}
\underline{c_{e}}-\underline{c_{b}}<(\gamma-\alpha) b \\
\underline{c_{e}}<(\gamma-\beta) b
\end{gathered}
$$

ii. Já quanto ao político incompetente, assenta-se a premissa de que o incremento de custos com o desempenho da função fiscalizatória (estratégia " $e$ "), com relação à proposição de leis particularistas (estratégia " $b$ ") ou irrelevantes (estratégia " $c$ "), mais do que compensa o maior retorno eleitoral. Pelo fato de a função fiscalizatória ser muito custosa ao político incompetente, ele tenta maximizar o número de votos com o que não exige competência, ainda que o retorno eleitoral seja baixo:

$$
\begin{gathered}
\overline{c_{e}}>(\gamma-\beta) b \\
\overline{c_{e}}-\overline{c_{b}}>(\gamma-\alpha) b
\end{gathered}
$$




\section{REVISTA ESTUDOS INSTITUCIONAIS}

\subsection{Bem-estar social resultante}

Para se avaliar o efeito social da decisão do político, convém computar a função de bem-estar social resultante, que é dada por:

$$
B E S=\pi \cdot b-(1-\pi) \cdot t-j
$$

Na expressão acima, $j$ é o custo administrativo de provocar a atuação do sistema de controle de constitucionalidade. Ou seja, $j=1$ se a lei for inconstitucional e $j=0$ se for constitucional; $\pi$ corresponde à parcela da população efetivamente beneficiada pela lei; e $t$ é o custo de oportunidade da proposta de lei que beneficia somente parte da sociedade, reduzindo o montante de recursos disponíveis para beneficiar os demais cidadãos.

Quanto ao bem-estar, assume-se que:

a) Estratégia a: a proposição de projetos de leis e políticas públicas que beneficiam a sociedade como um todo somente terão efeitos sobre o bem-estar social $(b)$, se não forem invalidadas pelo Poder Judiciário, no curto ou no longo prazo, caso contrário, o bem-estar social será negativo e corresponderá ao custo de utilizar o sistema de controle de constitucionalidade. Portanto, na situação atual em que não há autonomia subnacional, o bem-estar social será $-j$, que corresponde ao custo administrativo de provocar a atuação do sistema de controle de constitucionalidade. Por outro lado, se aos legislativos locais for dada competência para essas leis, o bemestar social será $B E S=b$.

b) Estratégia b: propor projetos de leis particularistas aumenta o bem-estar da parcela da sociedade $\alpha$ relativa ao grupo de interesse beneficiado pelas medidas particularistas, mas gera prejuízos aos demais grupos que não foram beneficiados. Portanto, o bem-estar social será: $B E S=\alpha \cdot b-(1-\alpha) \cdot t$

c) Estratégia c: os projetos de leis irrelevantes não trazem qualquer benefício real à sociedade: $B E S=0$.

d) Estratégia d: projetos de leis inconstitucionais e populistas não trazem verdadeiros ganhos sociais, uma vez que serão invalidadas em algum momento, mas implicam sociais, diante da mobilização da máquina estatal para a declaração da inconstitucionalidade dessas leis, i.e., $B E S=-j$.

e) Estratégia $e$ : a atividade fiscalizatória produz benefícios à sociedade $(\gamma . b)$, apesar de em menor nível que a estratégia " $a$ ", 


\section{Atuação do Poder Legislativo EstaduAL}

por melhorar a qualidade do gasto público e a eficiência do governo. Nesse caso, $B E S=\gamma \cdot b$.

\section{Caso 1: Reduzida competência constitucional das assembleias legislativas (situação atual)}

Descritos os elementos e as hipóteses do modelo, apresenta-se, em primeiro lugar, a forma extensiva da escolha do deputado estadual na situação atual, em que há insuficiente competência constitucional para proporem leis e políticas públicas que de fato beneficiem a sociedade como um todo. Na figura a seguir, a primeira coordenada em cada vetor de payoffs corresponde ao retorno para o deputado, enquanto a segunda corresponde ao bem-estar social resultante.

Figura 2 - reduzida competência constitucional das assembleias legislativas

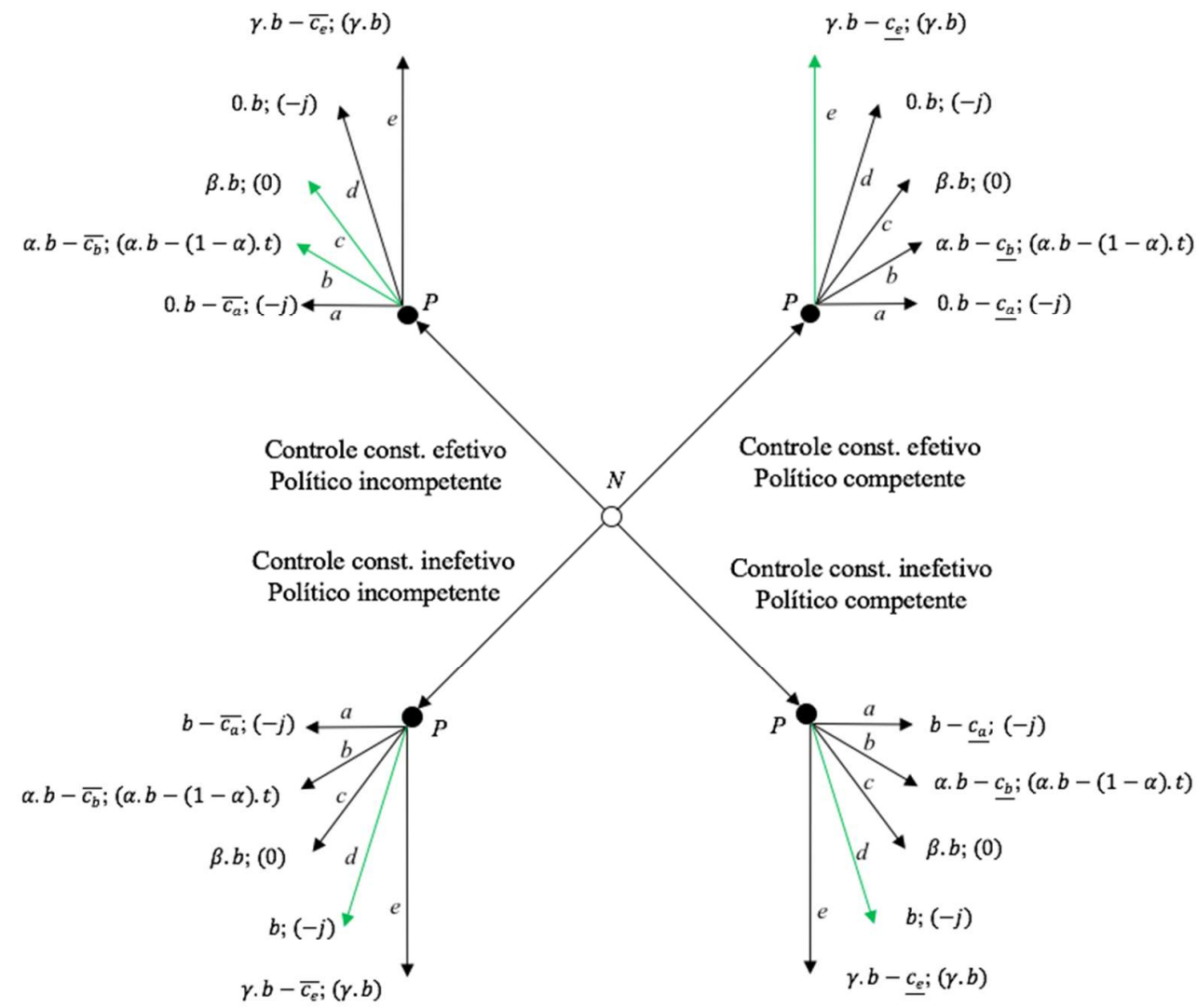

Fonte: elaboração própria 


\section{REVISTA ESTUDOS INSTITUCIONAIS}

A primeira coordenada em cada vetor de payoffs corresponde ao retorno para o deputado; a segunda corresponde ao bem-estar social resultante.

Nesse primeiro caso, sempre que o sistema de controle de constitucionalidade for inefetivo, a edição de políticas inconstitucionais será a estratégia escolhida pelo deputado estadual, qualquer que seja seu tipo, pois não incorrerá em custos e obterá maior retorno eleitoral, ao enganar os eleitores. Daí se extrai a essencialidade do controle de constitucionalidade para impor limites às estratégias oportunistas dos políticos.

Em outros termos, quando o controle é inefetivo, o deputado estadual não tem limites ao uso da atividade parlamentar para maximizar o número de votos na próxima eleição. Ele preferirá enganar os eleitores, fingindo que tem competência para fazer o que não pode, a incorrer nos custos de experimentar, a se engajar na melhoria das políticas públicas vigentes, ou a desenvolver a atividade fiscalizatória. A preferência por essa escolha "de facilidade" fica ainda mais evidente no caso de políticos incompetentes, cujos custos das demais alternativas são ainda maiores. $\mathrm{O}$ resultado é a proposição de leis populistas que em um primeiro momento parecem boas para todos, mas, por sobrepor atribuições e desestruturar a relação entre os poderes e os demais entes, gera mais prejuízos do que benefícios à sociedade.

Por outro lado, se o judiciário for efetivo, então o político do tipo incompetente escolherá ou uma política particularista ou uma política publicitária, a depender da relação custo-benefício entre elas. De fato, se $\beta b>\alpha b-\overline{c_{b}}$, ou seja, $\overline{c_{b}}<(\alpha-\beta) b$, então escolherá propor políticas particularistas. Já se $\overline{c_{b}} \geq(\alpha-\beta) b$, o deputado escolherá propor leis irrelevantes.

Conforme descrito na seção anterior, o sistema log-rolling tende a diminuir o custo da proposição de leis particularistas. Desse modo, em assembleias legislativas em que o sistema de log-rolling funcionar melhor, o político incompetente tende a escolher políticas particularistas. Por outro lado, se esse sistema de reciprocidade não estiver funcionando bem - seja por questões político-partidárias, seja porque a apresentação de leis particularistas não é a melhor estratégia para os demais pares da assembleia ${ }^{12}-$, o político incompetente tem maior propensão a propor projetos de lei irrelevantes.

\footnotetext{
${ }^{12}$ Os parlamentares aprovam os projetos uns dos outros, porque ambos visam a atender interesses particularistas diferentes. A partir dos insights até o momento obtidos, esse mecanismo de cooperação só funcionará bem se não for vantajoso para nenhum dos parlamentares adotar outra estratégia melhor, visto que se o deputado conseguir obter
} 
Observe-se ainda que o uso da estratégia de proposição de leis inúteis dependerá de fatores institucionais exógenos relativos à transparência do conteúdo das proposições e do esclarecimento da população acerca da sua qualidade.

Os dados empíricos parecem evidenciar que a maioria das assembleias legislativas estaduais se encontram em um desses três últimos cenários.

Enfim, se o sistema de controle de constitucionalidade for efetivo e o político for competente, ele escolherá a atividade fiscalizatória, que lhe dará maior retorno eleitoral, situação que também maximiza o bem-estar social. Nesse contexto, dado o custo e a ausência de competências constitucionais associadas à proposição de políticas que beneficiem a sociedade como um todo, o político nunca escolherá propor projeto de lei que tem o potencial de maximizar o bem-estar social. Ou seja, no contexto constitucional atual, os deputados estaduais não possuem incentivos para se empenhar na produção de legislação relevante, inovadora e que busque o aprimoramento da realização do interesse público e da efetivação de direitos fundamentais dos jurisdicionados pela via legislativa. A solução second best é investir na fiscalização.

Uma última conclusão que pode ser alcançada por meio dessa modelagem é a de que a capacitação dos membros das assembleias legislativas para o desempenho da função fiscalizatória - criando-se ambiente institucional propício para essa atividade, tal como ocorreu na Assembleia Legislativa de Minas Gerais ${ }^{13}$ - tem condão de incentivar políticos do tipo incompetentes, que antes propunham leis irrelevantes ou particularistas, a investirem na fiscalização do governo estadual como meio de obtenção de votos.

Nessa hipótese, diminuindo-se o número de deputados tendentes a propor políticas particularistas porque vislumbram a fiscalização como atividade mais eficiente para maximizar a chance de ser reeleito, o sistema de log-rolling perderá efetividade, intensificando a tendência à escolha da estratégia da fiscalização.

Para efeito de comparação, analisa-se o que ocorreria no caso de um federalismo mais verdadeiro em que as assembleias legislativas locais tivessem, sim, competência constitucional para elaborar lei ou política pública que beneficia toda a sociedade (estratégia " $a$ ").

votos da população como um todo, ele não ficará na dependência de aprovar o projeto do outro deputado para conseguir apoio de certo grupo de interesse pela aprovação desse projeto como estratégia para se reeleger.

13 Uma possibilidade seria criar estrutura de fiscalização e de análise de dados financeiros (ex.: ampliar acesso ao SIAFI, Contas Abertas). 


\section{REVISTA ESTUDOS INSTITUCIONAIS}

\section{Caso 2: Ampla Competência Constitucional às Assembleias Estaduais (situação potencial)}

Em uma situação hipotética - passível de ser implementada a partir (i) da ampliação das competências estaduais, realizada pela interpretação do Supremo Tribunal Federal, e/ou (ii) da implementação da proposta de se permitir a proposição de projetos de lei em conjunto com o governador -, o deputado é dotado de competências constitucionais suficientes para propor política pública que substancialmente implique benefícios sociais.

Figura 3 - Ampla competência constitucional às assembleias legislativas

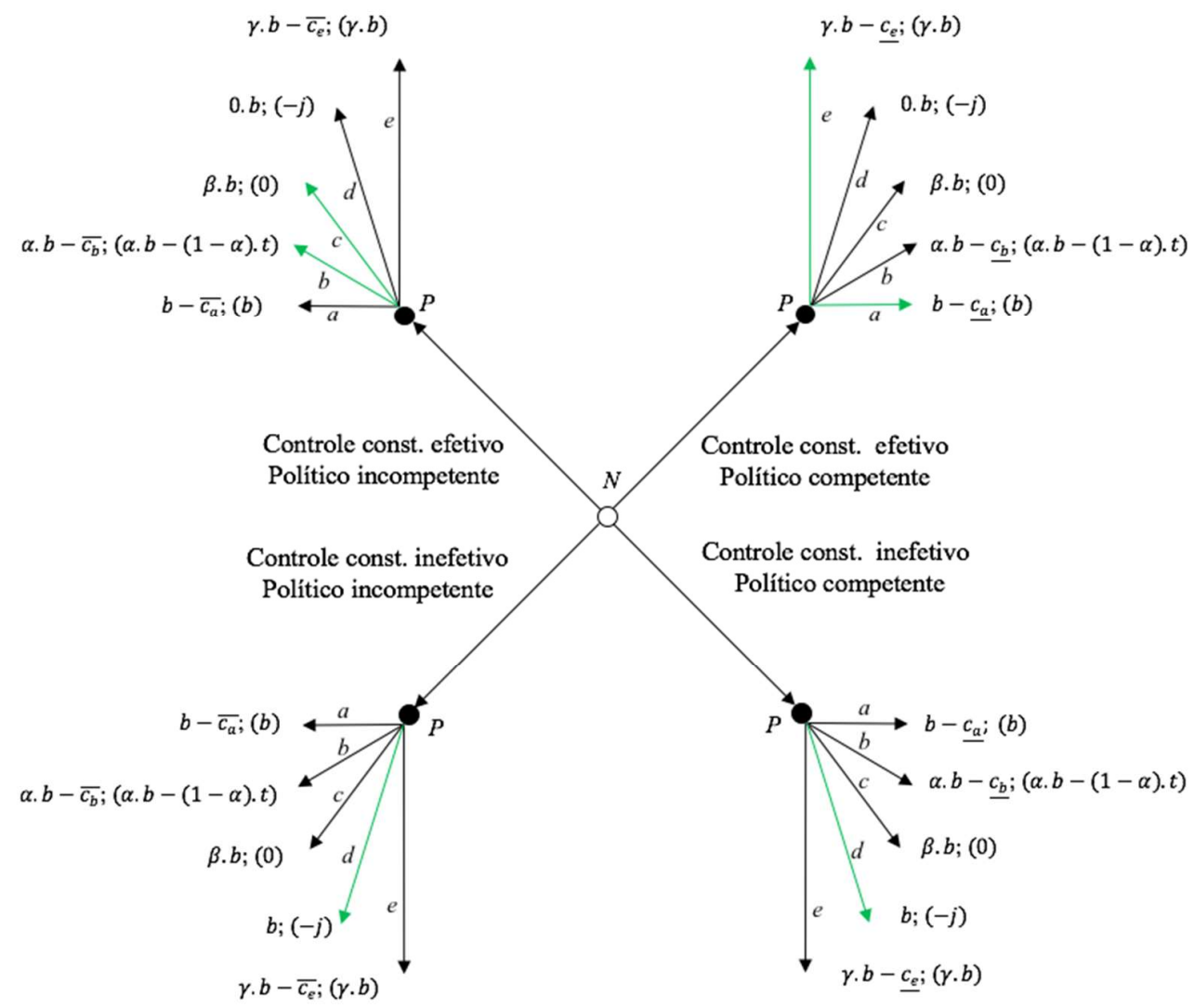

Fonte: elaboração própria 
A única diferença com relação à situação anterior é a de que, nesse caso, a estratégia " $a$ " não tem mais seus retornos eleitorais interrompidos pela declaração de inconstitucionalidade.

Considere-se agora os diferentes casos. Se o controle de constitucionalidade for inefetivo, continua sendo uma estratégia dominante para o deputado escolher projetos inconstitucionais e populistas (estratégia " $d$ "), pois esses não implicam em custos para ele, diferentemente da elaboração de uma política pública de qualidade.

Já se o sistema de controle de constitucionalidade for efetivo e o político for incompetente, ele novamente comparará os benefícios relativos e, ainda que o benefício seja maior na política global que na opção fiscalizatória, pelas hipóteses do modelo, ele ainda escolherá entre políticas particularistas e políticas para publicidade.

Finalmente, se o controle for efetivo e o político for competente, o político passa a dispor de uma opção adicional para obter votos, a estratégia " $a$ ", que ele comparará com o foco em fiscalização. Se, por um lado, a política global envolve maior custo, ela também resulta, agora, em maior efeito político eleitoral. Portanto,

Se $\overline{c_{a}}-\overline{c_{e}}>(1-\gamma) b$, então escolherá dedicar-se à fiscalização.

Se $\overline{c_{a}}-\overline{c_{e}} \leq(1-\gamma) b$, então escolherá projetos globais.

Note que, estritamente falando, o foco em políticas globais proporciona um maior bem-estar social que o foco em fiscalização. No entanto, as duas atividades geram um retorno social bem superior às demais. Além disso, o presente modelo não incorpora possíveis ganhos de escopo quando os políticos como um todo focam nas duas atividades, de fiscalização e de proposição de políticas relevantes que maximizem o bem-estar global, o que é possível quando é dado à assembleia local competência jurisdicional para tanto.

Da modelagem, observa-se que somente é melhor para o deputado estadual investir na proposição de leis e políticas públicas que efetivamente aumentarão o bem-estar social na hipótese específica em que o controle seja efetivo e o político competente. Nas outras hipóteses as soluções propostas pela teoria dos laboratórios legislativos não conseguirão reverter os incentivos distorcidos à produção de leis particularistas e irrelevantes. Em outras palavras, se o deputado não for qualificado o bastante para conseguir formular boas políticas públicas e o controle de constitucionalidade das leis estaduais não for efetivo, a expansão de suas competências constitucionais não fará com que ele passe a ser capaz de aprimorar a atuação legislativa dos estados. 


\section{REVISTA ESTUDOS INSTITUCIONAIS}

\section{CONCLUSÕES}

A análise dos modelos propostos evidencia que, na ausência de competência constitucional das assembleias legislativas, o melhor equilíbrio que se pode almejar é aquele em que o político foca seus esforços na atividade fiscalizatória. No entanto, esse equilíbrio nunca é atingido se o sistema de controle de constitucionalidade do estado for inefetivo e o político for incompetente.

Já no cenário hipotético no qual os membros das assembleias legislativas passem a ter competência constitucional para propor leis e políticas que beneficiem toda sociedade, quando o judiciário é efetivo, o político competente escolherá entre o foco em fiscalização ou o foco em políticas globais, ambas mais desejáveis do ponto de vista do bem-estar social.

Ao cabo do exposto, as evidências empíricas e a modelagem econômica sugerem que o atual desenho institucional presente nos estados brasileiros gera incentivos para que os deputados estaduais produzam leis particularistas, irrelevantes e inconstitucionais, quando o funcionamento dos mecanismos de controle dessas leis não é efetivo e/ou o deputado estadual não possui a competência necessária para desenvolver atividade parlamentar que beneficia a sociedade como um todo.

Conclui-se também que a abertura do federalismo deve ser acompanhada (i) da possibilidade de proposição de projetos de leis conjuntos entre deputados estaduais e governadores, (ii) da competência individual e institucional do deputado para elaborar políticas públicas que melhorem o bem-estar da sociedade como um todo, (iii) da efetividade do controle de constitucionalidade das leis estaduais. Assim sendo, a efetividade prática do panorama traçado pela teoria dos laboratórios legislativos dependeria, não só da descentralização do modelo federal, mas de muitos outros fatores que definem os incentivos que incidem sobre os membros do Poder Legislativo a nível subnacional.

Tais fatores não podem deixar de ser analisados e regulados em conjunto com o processo de abertura do federalismo, para que o aprimoramento institucional pretendido não se reverta na deterioração das instituições federativas e da sua capacidade de prover bens e serviços públicos de qualidade. 


\section{REFERÊNCIAS}

ABRUCIO, F. L. A coordenação federativa no Brasil: a experiência do período FHC e o desafio do governo Lula. Revista de Sociologia e Política, v. 24, 2005.

ALMEIDA, Fernanda Dias Menezes. Competências na Constituição de 1988. 2. ed., São Paulo: Editora Atlas, 2000.

ALMEIDA, Kelly; RODRIGUES, Larissa. Justiça derruba 77\% de leis aprovadas pela CLDF e questionadas pelo MP. Metropoles, 14 mar 2017. Disponível em: <https://www.metropoles.com/distrito-federal/politicadf/justica-derruba-77-de-leis-aprovadas-pela-cldf-e-questionadas-pelomp>. Acesso em: 29 nov. 2018.

MINAS GERAIS. Assembleia Legislativa. Políticas públicas ao seu alcance. 2018. Disponível em: <https://politicaspublicas.almg.gov.br/>. Acesso em 20/06/2018.

BELLON, Gabriel L. A. Constituições Estaduais pós-1989: o processo de emendamento e seus determinantes. 2016. Dissertação apresentada ao Programa de Pós-Graduação em Ciência Política do Departamento de Ciência Política da Faculdade de Filosofia, Letras e Ciências Humanas da Universidade de São Paulo, São Paulo, 2016.

CONSULTOR JURÍDICO. Anuário da Justiça Brasil 2018. Disponível em: $<$ https://www.conjur.com.br/loja/item/anuario-justica-brasil-2018>.

Acesso em: 29 nov. 2018.

FIGUEIREDO, Argelina Cheibub. Prefácio. In: SANTOS, Fabiano (org.). O Poder Legislativo nos Estados: diversidade e convergência. Rio de Janeiro: Editora FGV, 2001. 


\section{REVISTA ESTUDOS INSTITUCIONAIS}

HOSLI, Madeleine O. Federalism, subsidiarity and interest groups: a political economy perspective. European Institute of Public Administration (EIPA). In: UNSPECIFIED, Charleston: SC, 1995.

LEONCY, Léo Ferreira Leoncy. "Princípio da simetria" e argumento analógico: $\mathrm{O}$ uso da analogia na resolução de questóes federativas sem solução constitucional evidente. 2011. Tese de doutorado em Direito na USP, 2011.

SALES, Leonardo. Um raio-x da atuação das assembleias legislativas. 2017. Disponível em: $<$ https://leosalesblog.wordpress.com/2017/10/30/um-raio-x-da-atuacaodas-assembleias-legislativas/;>. Acesso em 10/11/2017.

TAVARES, André Ramos. Aporias acerca do "condomínio legislativo" no Brasil: uma análise a partir do STF. Revista Brasileira de Estudos Constitucionais. Belo Horizonte: ano 2, n.6, abr/jun, 2008.

VIANNA, Luiz Werneck; BURGOS, Marcelo Baumann; SALLES, Paula Martins. Dezessete anos de judicialização da politica. Tempo Social. v. 19, n. 2, 2007.

RECEBIDO EM: 05/08/2018. ACEITO EM: 07/09/2018. 